\title{
Association between dose-volume parameters and acute bone marrow suppression in rectal cancer patients treated with concurrent chemoradiotherapy
}

\author{
Nan Li ${ }^{1}$, Xue Liu ${ }^{1}$, Fushan Zhai ${ }^{1}$, Bing Liu ${ }^{1}$, Xiaohui Cao ${ }^{1}$, Shuyan Li ${ }^{1}$, Minxian Zhang ${ }^{1}$ \\ and Ming Liu ${ }^{1}$ \\ ${ }^{1}$ Department of Radiotherapy and Oncology, Third Hospital of Hebei Medical University, Shijiazhuang, China \\ Correspondence to: Ming Liu, email: 13313012920@163.com \\ Keywords: concurrent chemoradiotherapy, acute bone marrow suppression, dose-volume parameters, rectal cancer, pelvic \\ bone marrow \\ Received: July 13,2017 Accepted: August 27, $2017 \quad$ Published: October 06, 2017 \\ Copyright: Li et al. This is an open-access article distributed under the terms of the Creative Commons Attribution License 3.0 \\ (CC BY 3.0), which permits unrestricted use, distribution, and reproduction in any medium, provided the original author and source \\ are credited.
}

\section{ABSTRACT}

Concurrent chemoradiotherapy is one of the main treatments for rectal cancer. Bone marrow suppression is one of the critical factors that affect the progress of radiotherapy. We aimed to explore the association of incidence of acute bone marrow suppression with dose-volume parameters of pelvic bone marrow among rectal cancer patients with concurrent chemoradiotherapy. We retrospectively analyzed $\mathbf{5 0}$ rectal cancer patients for multivariate logistic regression analyses. Three subdomains of pelvic bone marrow (PBM), bilateral ilium (IBM), lower pelvis (LPBM), and lumbosacral spine (LSBM) were assigned. The radiation dose-volume parameters from the three subdomains and the whole pelvis were evaluated. Compared to Grade 0-1 leukopenia patients, $\geq$ Grade 2 leukopenia patients exhibited significantly higher levels of IBM $\mathrm{v}_{20}, \mathrm{v}_{25}, \mathrm{v}_{35}$, mean dose (Dmean), LPBM $\mathrm{v}_{20}, \mathrm{v}_{25}, \mathrm{v}_{30}$, LSBM $\mathrm{v}_{15}$, PBM $\mathrm{v}_{15}, \mathrm{v}_{20}$, and PTV. The PBM $V_{20}$ of $\geq G$ rade 2 neutropenia patients was significantly higher than that of Grade 0-1 neutropenia patients. Multivariate analysis have demonstrated that IBM $V_{20}$ and LSBM $V_{15}$ were the independent factors affecting $\geq$ Grade 2 leukopenia. There is a correlation between low dose-volume parameters with acute bone marrow suppression. IBM $V_{20}$, LSBM $V_{15}$ and PBM $V_{20}$ can be employed as the predictors of acute bone marrow suppression.

\section{INTRODUCTION}

As a common malignant tumor, the incidence rate of rectal cancer had increased from 2000 to 2011 [1]. Currently, concurrent chemoradiotherapy is one of the main treatments for rectal cancer, which suppresses tumor local recurrence as well as improves overall survival [2, 3]. During concurrent chemoradiotherapy, Intensity Modulated Radiotherapy (IMRT) compares with Three-Dimensional Conformal Radiation Therapy (3-DCRT), IMRT exhibits dosimetric advantages in elevating conformality and dose gradient within target volume. IMRT significantly reduces organ-atrisk exposure [4, 5]. However, both radiotherapy and chemotherapy cause damages to bone marrow in different degree and loss of blood cells [6]. Hematological toxicity is a major cause of treatment interruptions which may lead to an increase in overall treatment time with a consequent detrimental effection. Bone marrow (BM), a primary hematopoietic tissue in humans, contains hematopoietic stem cells (HSCs), multipotent progenitors (MPPs), hematopoietic progenitor cell (HPCs), as well as multiple fully differentiated blood cells. Under normal physiological condition, HSCs are maintained in a quiescent state that is beneficial for lifelong hematopoiesis. Due to the short lifetime of granulocytes (6-8 hours), the first phenomenon of BM suppression is leukopenia(neutropenia). Irradiation to the BM cavity 
causes apoptosis and compromised proliferation of HSCs and progenitor cells. It also interrupts the resting state of HSCs, by inducing the cells from G0 phase into cell cycle, destroying the HSC niche [7]. Radiation not only induces BM suppression, but also directly kills granulocytes or causes chromosome alterations. The changes of microcirculation last for quite a long period. Because of their exuberant proliferation and low grade differentiation, BM and lymphoid tissues are extremely sensitive to radiation. Thus, the detrimental effects on $\mathrm{BM}$ are dependent on the dose, range, site and length of radiation. Hematopoietic bone marrow of healthy adults is mainly distributed in flat and irregular bones. More than $50 \%$ of hematopoietic bone marrow is found in hip, sacrum, proximal epiphysis of femur, and lumbosacral spine [8-9], all of which are within the irradiation range of radiation therapy for rectal cancer, inducing acute and chronic hematologic toxicity. Different drugs show remarkably different detrimental effects to bone marrow. Jin et al. [10] have found that leukopenia is the most severe side effect caused by capecitabine chemotherapy combined with radiotherapy in rectal cancer patients, since the incidences of Grade 2 and 3 leukopenia are $19.7 \%$ and $3.3 \%$, respectively. It has also been documented that $69 \%$ rectal patients receiving concurrent chemoradiotherapy with capecitabine develop leukopenia, and $4 \%$ of the patients develop $\geq$ Grade 3 leukopenia [11]. It has been reported that only $4 \%$ of the colon cancer patients receiving capecitabine chemotherapy develop bone marrow suppression, indicating minimal side effects to bone marrow [12]. Therefore, we assumed that radiation therapy may be the leading cause of hematologic toxicity during concurrent chemoradiotherapy for rectal cancer.

In the present study, we analyzed the development of acute bone marrow suppression in rectal cancer patients receiving concurrent chemoradiotherapy, and explored the association between acute bone marrow suppression and general clinical factors as well as dose-volume parameters of pelvic bone marrow. Our study may provide potential predictors for bone marrow suppression.

\section{RESULTS}

\section{Occurrence of acute bone marrow suppression}

During the procedure of concurrent chemoradiotherapy, 37 patients (74\%) developed acute bone marrow suppression, and the incidence of $\geq$ Grade 2 bone marrow suppression was $28.0 \%$ (14/50) (Table 1)

\section{Analysis of clinical factors}

The difference of gender, age, body mass index (BMI), clinical stage of the patients and surgery did not show significant impacts $(\mathrm{P}>0.05)$ on the occurrence of $\geq$ Grade 2 acute bone marrow suppression (Table 2)

\section{Univariate analysis of acute bone marrow suppression}

Our data unveiled an association between leukopenia and dose-volume parameters of BM radiation. Compared to the patients with Grade 0-1 leukopenia, the patients with $\geq$ Grade 2 leukopenia showed a remarkable increase of several dose-volume parameters, including IBM V $\mathrm{V}_{20}, \mathrm{~V}_{25}$, $\mathrm{V}_{35}$, Dmean, LPBM V $20, \mathrm{~V}_{25}, \mathrm{~V}_{30}, \mathrm{LSBM} \mathrm{V}_{15}, \mathrm{PBM} \mathrm{V}_{15}, \mathrm{~V}_{20}$, and PTV $(\mathrm{P}<0.05)$ (Table 3$)$. The PBM V $V_{20}$ of $\geq$ Grade 2 neutropenia patients was significantly higher than that of Grade $0-1$ neutropenia patients $(\mathrm{P}<0.05)$ (Table 4). ROC curve analysis demonstrated that the area under the curve (AUC) of PBM V $\mathrm{V}_{20}$ was 0.81 and the predicted threshold was $83.59 \%$ (Table 5, and Figure 1 Receiver operating characteristic curve of (ROC) PBM V $V_{20}$ as predictor of $\geq$ Grade 2 neutropenia). However, there was no significant difference in the dosimetric data between $\geq$ Grade 2 and Grade $0-1$ anemia and thrombocytopenia patients $(\mathrm{P}>0.05)$.

\section{Multivariate analysis of acute bone marrow suppression}

The dose-volume parameters of statistical significance in the univariate analysis were selected for subsequent multivariate analysis, and the results demonstrated that IBM $\mathrm{V}_{20}$ and LSBM $\mathrm{V}_{15}$ were significant associated with acute leukopenia based on logistic regression model $(\mathrm{P}<0.05)$ (Table 6). IBM V 20, LSBM V $_{15}$, and PBM V 20 were used for ROC curve analysis (Table 5). The AUC of IBM V $V_{20}$ and LSBM V ${ }_{15}$ were 0.759 and 0.709 , and predicted thresholds were $61.09 \%$ and $85.29 \%$, respectively (Figure 2 Receiver operating characteristic curve (ROC) generated by IBM V $\mathrm{V}_{20}$ and $\mathrm{LSBM} \mathrm{V}_{15}$ ).

\section{DISCUSSION}

Nowadays, concurrent chemoradiotherapy has been commonly employed for treatment of rectal cancer patients. Because of sensitization to radiotherapy caused by chemotherapy drugs, concurrent chemoradiotherapy has enhanced therapeutic outcomes. However, it should be noted that concurrent chemoradiotherapy is also accompanied with elevated damages to organs and overlaid hematopoietic toxicity, leading to increased incidence and extent of bone marrow suppression. Han et al. [13] and Duenas-Gonzalez et al. [14] have found that the incidence of $\geq$ Grade 3 bone marrow suppression is $40-60 \%$ in the cervical cancer and rectal cancer patients receiving concurrent chemoradiotherapy. It has been documented that the incidences of Grade 1-5 bone marrow suppression is $23 \%, 33 \%, 25 \%, 0 \%$, and $0 \%$, respectively, in the cervical patients during therapy [15]. Among the 50 patients enrolled in our study, the incidences of Grade 1-4 bone marrow suppression was $46.0 \%, 20.0 \%, 8.0 \%$, and $0 \%$, respectively, during the acute observation. 
Table 1: The occurrence of acute hematologic toxicity

\begin{tabular}{lccccc}
\hline & \multicolumn{5}{c}{ Grade } \\
\cline { 2 - 6 } Toxicity & $\mathbf{0 ( \% )}$ & $\mathbf{1}(\mathbf{\%})$ & $\mathbf{2 ( \% )}$ & $\mathbf{3 ( \% )}$ & $\mathbf{4 ( \% )}$ \\
\hline Leukopenia & $21(42)$ & $18(36)$ & $10(20)$ & $1(2)$ & $0(0)$ \\
Neutropenia & $38(76)$ & $7(14)$ & $4(8)$ & $1(2)$ & $0(0)$ \\
Anemia & $38(76)$ & $10(20)$ & $0(0)$ & $2(4)$ & $0(0)$ \\
Thrombocytopenia & $46(92)$ & $2(4)$ & $1(2)$ & $1(2)$ & $0(0)$ \\
\hline
\end{tabular}

Values are number (percentage).

Table 2: The relationship between clinical factors and incidence of bone marrow suppression (BMS) $\geq$ Grade 2

\begin{tabular}{|c|c|c|c|c|c|}
\hline \multirow[t]{2}{*}{ Clinical factors } & \multirow[t]{2}{*}{$\operatorname{case}(\mathbf{N})$} & \multicolumn{2}{|c|}{$\begin{array}{l}\text { The cases } \geq \text { Grade } 2 \text { acute bone } \\
\text { marrow suppression }\end{array}$} & \multirow{2}{*}{$\chi^{2}$ value } & \multirow{2}{*}{ P value } \\
\hline & & $\operatorname{case}(\mathrm{N})$ & incidence rate $(\%)$ & & \\
\hline Gender & & & & 0.043 & 0.551 \\
\hline male & 31 & 9 & 29.03 & & \\
\hline female & 19 & 5 & 26.32 & & \\
\hline Age & & & & 0.651 & 0.311 \\
\hline$<60$ years & 24 & 8 & 33.33 & & \\
\hline$\geq 60$ years & 26 & 6 & 23.08 & & \\
\hline BMI & & & & 0.021 & 0.446 \\
\hline$<23.34$ & 24 & 6 & 25 & & \\
\hline$\geq 23.34$ & 26 & 8 & 30.77 & & \\
\hline TNM stage & & & & 0.123 & 0.726 \\
\hline I-II & 16 & 5 & 31.25 & & \\
\hline III-IV & 34 & 9 & 26.47 & & \\
\hline Surgery & & & & 0.734 & 0.301 \\
\hline yes & 31 & 10 & 32.26 & & \\
\hline no & 19 & 4 & 21.05 & & \\
\hline
\end{tabular}

$\mathrm{BMI}=$ body mass index; TNM= T:tumor, N:lymph node, M:metastasis.

In a study involving 155 cervical cancer patients, Huang et al. [16] have reported that the development of bone marrow suppression is not significantly influenced by the general clinical factors, such as age, clinical stage, chemotherapy cycles, surgery, and methods of radiotherapy. Niu et al. [17] have retrospectively analyzed 99 patients with cervical cancer and concluded that bone marrow suppression is not associated with age, complications, clinical stage, tumor classification, chemotherapy regimen as well as course number of uterine artery infusion chemotherapy. The study of Mell et al. [6] has revealed that white blood cell nadir is correlated with female gender, low BMI and lymph node positivity, and neutrophil nadir is correlated with female gender and low BMI. Moreover, it has been reported that $\geq$ Grade 2 leukopenia is associated with cycle number of chemotherapy, and $\geq$ Grade 2 neutropenia is associated with cycle number of chemotherapy and T stage [18]. Single factor analysis in the present has demonstrated that acute bone marrow suppression is not significantly associated with gender, age, $\mathrm{BMI}$ and clinical stage of rectal cancer patients.

Bone marrow is considered a "parallel organ" in medical radiobiology. Thus, volume of radiation is directly related to the development of bone marrow 
Table 3: Grade 0 1 acute leukopenia VS. $\geq$ Grade 2 acute leukopenia dosimetry comparison

\begin{tabular}{|c|c|c|c|c|c|c|}
\hline \multirow{2}{*}{ DVH parameters } & \multicolumn{4}{|c|}{ acute leukopenia } & \multirow{2}{*}{$\mathbf{t}(\mathbf{z})$} & \multirow{2}{*}{$\boldsymbol{P}$} \\
\hline & Grade 0-1 & range & $\geq$ Grade 2 & range & & \\
\hline \multicolumn{7}{|l|}{ PBM } \\
\hline $\mathrm{V}_{15} \%$ & $74.8(27.63)^{*}$ & $14.12-90.03$ & $82(14.97)^{*}$ & $55.2-92.5$ & -2.073 & $0.038^{\circ}$ \\
\hline $\mathrm{V}_{20} \%$ & $66.52(31.12)^{*}$ & $10.8-83.76$ & $79(16.93)^{*}$ & $50.7-91.5$ & -2.471 & $0.013^{\circ}$ \\
\hline \multicolumn{7}{|l|}{ IBM } \\
\hline $\mathrm{V}_{20} \%$ & $54.41(29.38)^{*}$ & $0-83.29$ & $67.5(12.96)^{*}$ & $43.1-80$ & -2.6 & $0.009^{\circ}$ \\
\hline $\mathrm{V}_{25} \%$ & $39.9(20.98)^{\#}$ & $0-76.46$ & $54.59(13.61)^{\#}$ & $26.1-78$ & -2.769 & $0.01^{\diamond}$ \\
\hline $\mathrm{V}_{35} \%$ & $16(16.32)^{*}$ & $0-35.5$ & $21.47(3.21)^{*}$ & $6.9-46$ & -2.12 & $0.043^{\circ}$ \\
\hline Dmean, cGy & $2098(1076)^{*}$ & $29-3193$ & $2467(408)^{*}$ & $1805-3358$ & -2.166 & $0.03^{\circ}$ \\
\hline \multicolumn{7}{|l|}{ LPBM } \\
\hline $\mathrm{V}_{20} \%$ & $52.8(21.48)^{\#}$ & $2.35-90.41$ & $69.6(26.62)^{\#}$ & $18-100$ & -2.173 & $0.035^{\diamond}$ \\
\hline $\mathrm{V}_{25} \%$ & $39.39(19.58)^{\#}$ & $0.99-72.58$ & $55.42(26.13)^{\#}$ & $14.4-100$ & -2.224 & $0.031^{\circ}$ \\
\hline $\mathrm{V}_{30} \%$ & $24.31(15.34)^{\#}$ & $0.18-52.37$ & $37.46(23.1)^{\#}$ & $9.5-90$ & -2.233 & $0.03^{\diamond}$ \\
\hline \multicolumn{7}{|l|}{ LSBM } \\
\hline $\mathrm{V}_{15} \%$ & $87.17(36.44)^{*}$ & $0-100$ & $97.87(12.3)^{*}$ & $86.4-100$ & -2.097 & $0.036^{\circ}$ \\
\hline PTV, $\mathbf{c m}^{3}$ & $825.28(318.72)^{\#}$ & $94.27-1690.65$ & $1067.52(400.67)^{\#}$ & 410.3-1796 & -2.103 & $0.041^{\triangleright}$ \\
\hline
\end{tabular}

${ }^{\bullet}$ independent samples T test, ${ }^{\circ}$ Mann-Whitney U test.

\#Data presented as mean percentage, with standard deviation in parentheses.

*Data presented as median percentage, with quartile range in parentheses.

$\mathrm{PBM}=$ pelvic bone marrow; IBM= iliac bone marrow; LPBM= lower pelvis bone marrow; LSBM= lumbosacral Spine bone marrow; $\mathrm{V}_{15}, \mathrm{~V}_{20}, \mathrm{~V}_{25}, \mathrm{~V}_{30}, \mathrm{~V}_{35}=$ volume of bone marrow receiving 15, 20, 25, 30, 35Gy or more; DVH= dose-volume histogram; Dmean= the mean dose of iliac bone marrow; PTV= planning Target Volume.

Table 4: Grade 0 1 acute neutropenia VS. $\geq$ Grade 2 acute neutropenia dosimetry comparison

\begin{tabular}{lcccccc}
\hline & \multicolumn{5}{c}{ acute neutropenia } & \\
\cline { 2 - 6 } DVH parameters & Grade 0-1 & range & ZGrade 2 & range & $\mathbf{Z}$ & $\boldsymbol{P}$ \\
\hline PBM V $_{20}(\%)$ & $67.35(25.04)$ & $10.8-85$ & $85.08(31.29)$ & $50.73-91.5$ & -2.045 & 0.04 \\
\hline
\end{tabular}

$\mathrm{DVH}=$ dose-volume histogram $; \mathrm{PBM}=$ pelvic bone marrow $; \mathrm{V}_{20}=$ volume of bone marrow receiving $20 \mathrm{~Gy}$ or more. Data presented as median percentage, with quartile range in parentheses.

Table 5: DVH parameters predictive ablity of $\geq$ Grade 2 acute leukopenia and $\geq$ Grade 2 acute neutropenia

\begin{tabular}{lccccc}
\hline DVH parameter & AUC & boundary value (\%) & sensitivity (\%) & specificity (\%) & $\begin{array}{c}\text { Asymptotic 95\% } \\
\text { Confidence Interval }\end{array}$ \\
\hline $\mathrm{IBM} \mathrm{V}_{20}$ & 0.759 & 61.09 & 0.91 & 0.67 & $0.616-0.902 \star$ \\
$\mathrm{LSBM} \mathrm{V}_{15}$ & 0.709 & 85.29 & 1 & 0.49 & $0.559-0.858 \boldsymbol{1}$ \\
$\mathrm{PBM} \mathrm{V}$ & 0.81 & 83.59 & 0.75 & 0.96 & $0.507-1^{\bullet}$ \\
\hline
\end{tabular}

$\triangle$ acute leukopenia, $\bullet$ acute neutropenia.

$\mathrm{PBM}=$ pelvic bone marrow; IBM= iliac bone marrow; LSBM= lumbosacral spine bone marrow; $\mathrm{V}_{15}, \mathrm{~V}_{20}=$ volume of bone marrow receiving 15, 20Gy or more; $\mathrm{DVH}=$ dose-volume histogram. 
Table 6: Logistic multifactor analysis of bone marrow DVH with $\geq$ Grade 2 acute leukopenia

\begin{tabular}{lccccc}
\hline DVH parameters & B & SE & Wald & $\boldsymbol{P}$ & $\operatorname{Exp}(\mathbf{B})$ \\
\hline IBM V $_{20}$ & 1.692 & 0.782 & 4.682 & 0.03 & 5.431 \\
LSBM V $_{15}$ & 0.903 & 0.386 & 5.458 & 0.019 & 2.467 \\
\hline
\end{tabular}

Abbreviations: IBM= Iliac Bone Marrow; LSBM= Lumbosacral Spine Bone Marrow; $\mathrm{V}_{15}, \mathrm{~V}_{20}=$ volume of bone marrow receiving 15, 20Gy or more; DVH= Dose-volume histogram.

suppression. Acute BM suppression is accompanied with irradiation induced apoptosis of HSCs and hematopoietic progenitor cells (HPCs) as well as disturbed proliferation of HPCs. Radiation not only induces BM suppression, but also directly kills granulocytes or causes chromosome alterations. The changes of microcirculation last for quite a long period. Mell et al. [8] has found that pelvis $\mathrm{V}_{10}$ is associated with $\geq$ Grade 2 leukopenia and neutropenia. The patients with pelvis $\mathrm{V}_{10}$ $\geq 90 \%$ are more susceptible to $\geq$ Grade 2 bone marrow suppression compared to those with pelvis $\mathrm{V}_{10}<90 \%$, while acute bone marrow suppression is not correlated

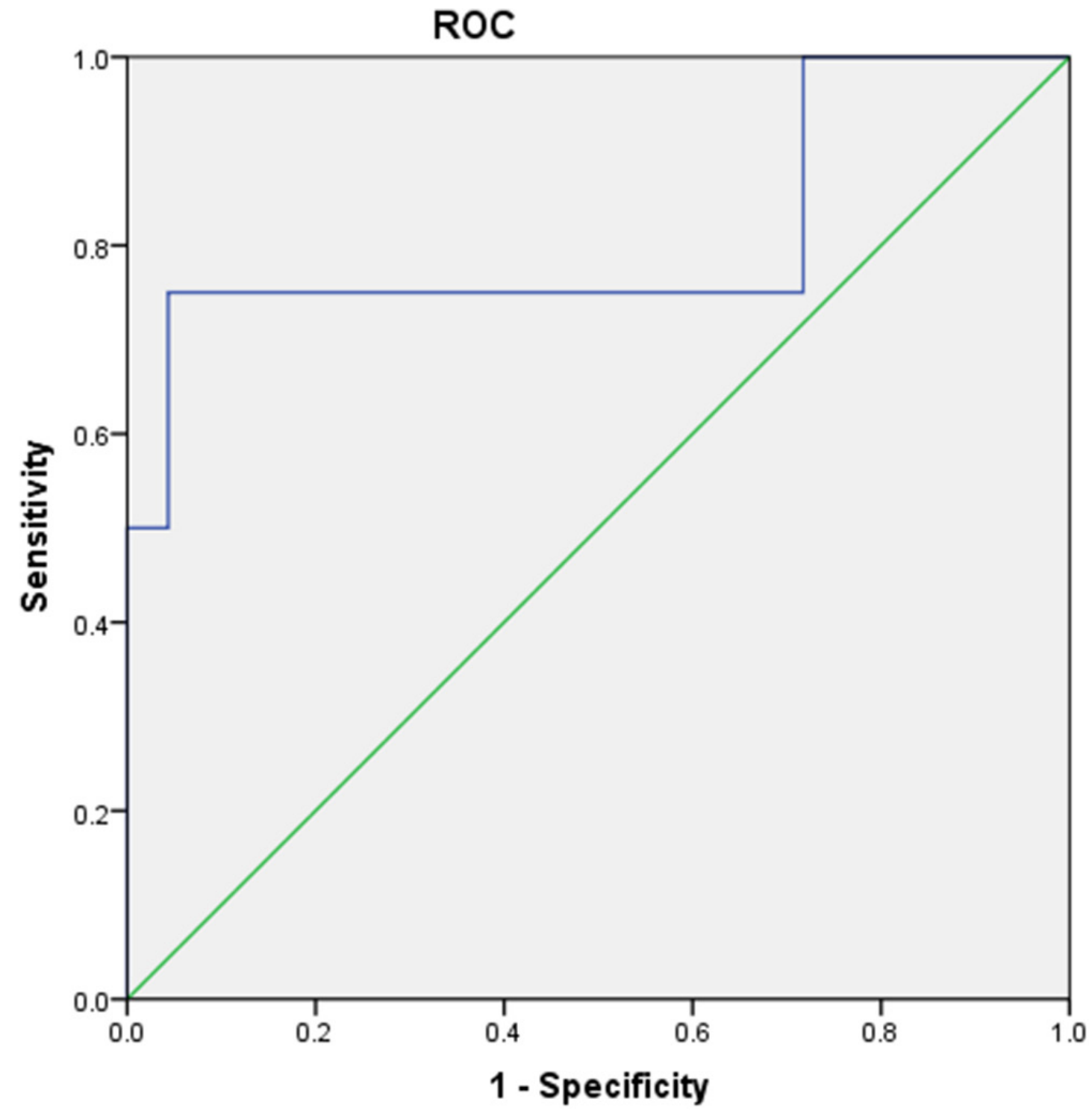

Figure 1: Receiver operating characteristic curve (ROC) of $\mathbf{P B M ~} \mathbf{V}_{\mathbf{2 0}}$ as predictor of $\geq$ Grade2 neutropenia. $P B M V_{20}$ was significant associated with $\geq$ Grade 2 neutropenia $(A U C=0.81, P=0.019)$. $P B M=$ pelvic bone marrow; $V_{20}=$ the volume of bone marrow receiving 20 Gy or more. 


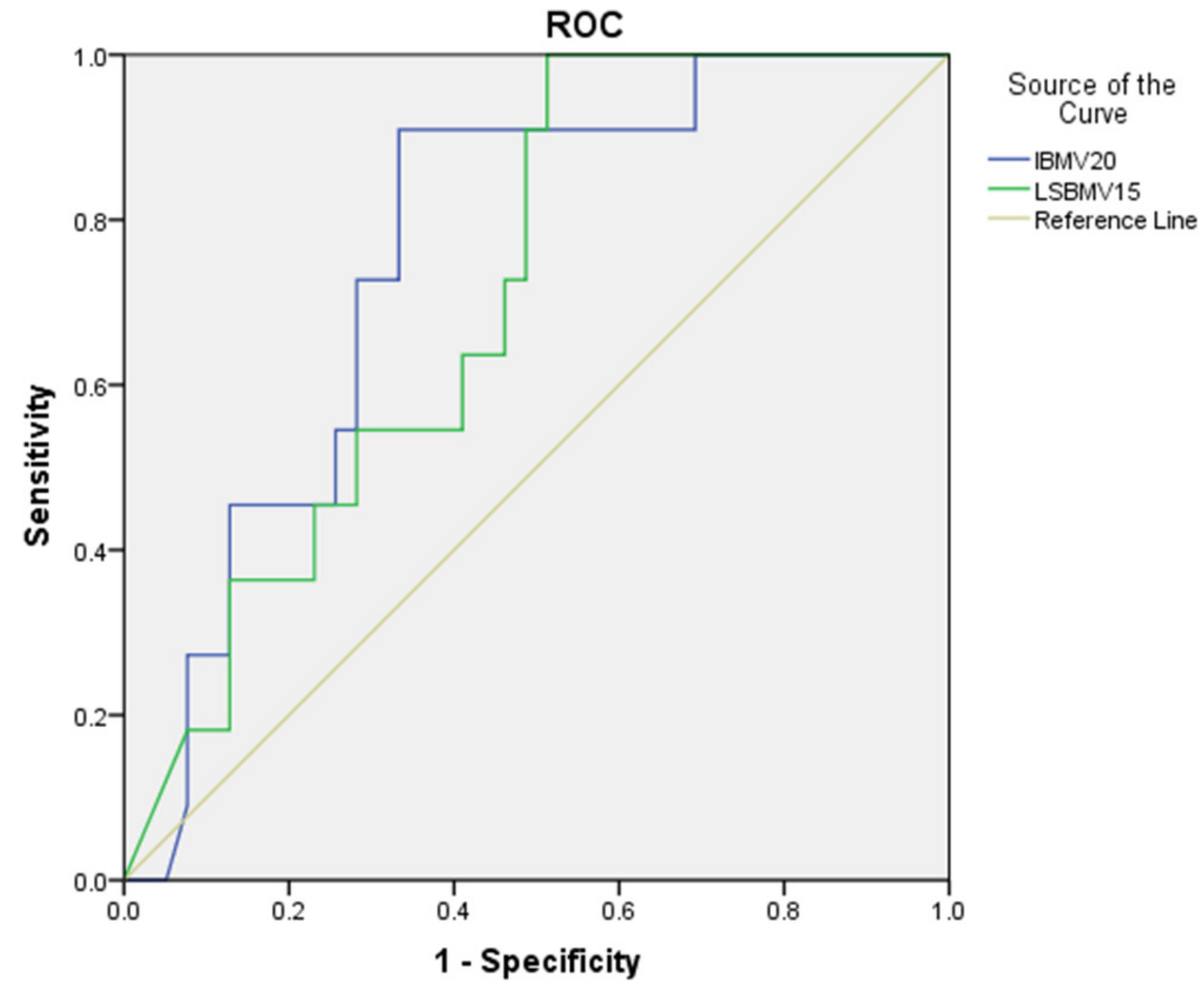

Diagonal segments are produced by ties.

Figure 2: Receiver operating charicteristic curve (ROC) of IBM $V_{20}$ and $L S B M V_{15}$ as predictor of $\geq$ Grade2 leukopenia. The blue line is Iliac Bone Marrow $\mathrm{V}_{20}\left(\mathrm{AUC}=0.81, \mathrm{P}=0.03\right.$ ). The green line is Lumbosacral Spine Bone Marrow $\mathrm{V}_{15}(\mathrm{AUC}=0.709$, $\mathrm{P}=0.019)$. IBM $\mathrm{V}_{20}$ and $L S B M \mathrm{~V}_{15}$ were significant associated with $\geq$ Grade2 leukopenia. Abbreviations: IBM= Iliac Bone Marrow; LSBM $=$ Lumbosacral Spine Bone Marrow ; $\mathrm{V}_{15}=$ The volume of bone marrow receiving $15 \mathrm{~Gy}$ or more ; $\mathrm{V}_{20}=$ The volume of bone marrow receiving $20 \mathrm{~Gy}$ or more.
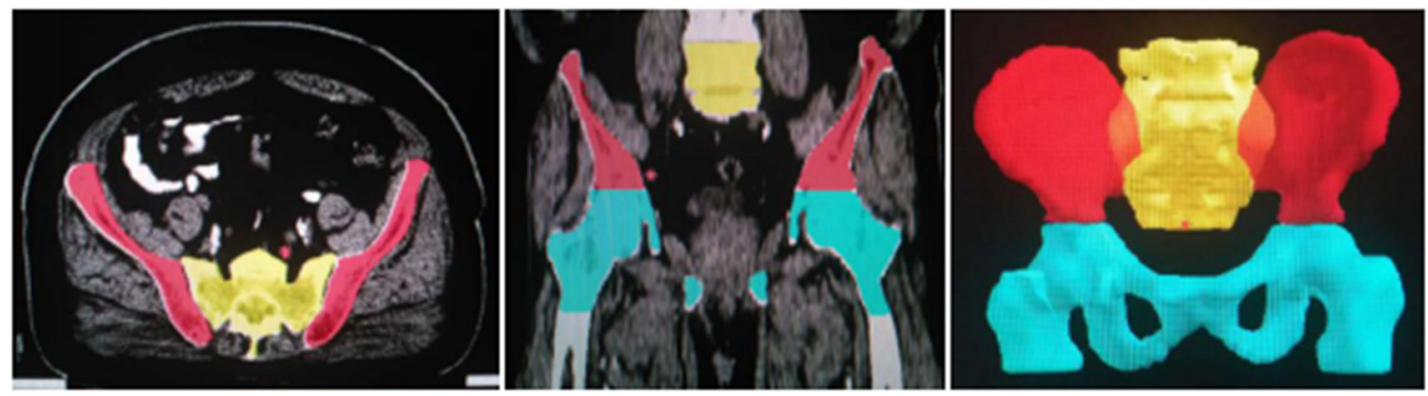

Figure 3: 2D and 3D pictures of contour of pelvic bone. The red zones are bilateral ilium, the light blue zones are lower pelvis, and the yellow zone is lumbosacral spine. 
with $\mathrm{V}_{30}$ and $\mathrm{V}_{40}$. A study involving 108 patients has demonstrated that pelvis $\mathrm{D}_{\max } \leq 57$ Gy can reduce the occurrence of anemia, and pelvis $\mathrm{V}_{10}$ is associated with bone marrow suppression (threshold $=87 \%$ ) [18]. Huang et al. [16] have retrospectively analyzed 155 patients and found that pelvis $\mathrm{V}_{15}$ is an independent risk factor of acute bone marrow suppression (threshold = $88 \%$ ). Other studies have also unveiled the association between bone marrow suppression and low dose-volume parameters [19, 20].

Rose et al. have discovered that hematopoietic BM is mainly distributed in lumbosacral spine and pubis, while inactive $\mathrm{BM}$ is mainly distributed in ilium, ischium and proximal epiphysis of femur [20]. Using MRI and SPECT, Roeske et al. have found that hematopoiesis active domains are located in lumbosacral spine, middle ilium and iliac crest [21]. Thus, hematopoietic BM is not evenly distributed in the three sub-domains of pelvis: bilateral ilium, lower pelvis, and lumbosacral spine. Our data have revealed that $\geq$ Grade 2 leukopenia patients exhibit significantly higher levels of IBM $\mathrm{V}_{20}, \mathrm{~V}_{25}, \mathrm{~V}_{35}$, mean dose, LPBM V $\mathrm{V}_{20}, \mathrm{~V}_{25}, \mathrm{~V}_{30}, \mathrm{LSBM} \mathrm{V}_{15}$, pelvis $\mathrm{V}_{15}$, $\mathrm{V}_{20}$, and PTV compared to the Grade 0-1 leukopenia patients, and the PBM $V_{20}$ of $\geq$ Grade 2 neutropenia patients is significantly higher than that of Grade 0-1 neutropenia patients, suggesting that $\geq$ Grade 2 bone marrow suppression is associated with low dose-volume of pelvis as well as each subdomain. Logistic regression modeling has demonstrated that IBM V $V_{20}$ and LSBM V are the independent factors correlated with $\geq$ Grade 2 leukopenia. ROC curve analyses of IBM V ${ }_{20}, \mathrm{LSBM} \mathrm{V}_{15}$ and PBM V ${ }_{20}$ have determined their thresholds $(61.09 \%$, $85.29 \%$ and $83.59 \%$, respectively), which may serve as optimal dosimetric thresholds.

PET-CT and MRI have been currently used for delineation of hematopoietic bone marrow and studies of bone marrow-sparing. MRI has been used to delineate hematopoietic bone marrow and to setup dose limitation, and the results have unveiled that the radiation dose to hematopoietic bone marrow $\mathrm{V}_{5}$ and $\mathrm{V}_{10}$ is significantly correlated to the incidence and severity of hematologic toxicity [22]. Liang et al. [23] have used PET-CT and MRI to delineate functional bone marrow and divided pelvic cancer patients into two groups: functional BM-IMRT group and total BM-IMRT group. There is a striking difference of functional bone marrow $\mathrm{V}_{10}$ and $\mathrm{V}_{20}$ between these two groups, indicating a better bone marrow protection can be achieved by singularly limiting dose of functional bone marrow instead of total bone marrow.

In conclusion, acute bone marrow suppression in the rectal patients receiving concurrent chemoradiotherapy is significantly associated with decreased dose-volume parameters. Three independent risk factors, IBM $\mathrm{V}_{20}$, LSBM V $V_{15}$, and PBM V 20 , may be employed to predict the occurrence of acute bone marrow suppression when designing therapeutic plans. Next, we will carry out perspective studies on the development of bone marrow

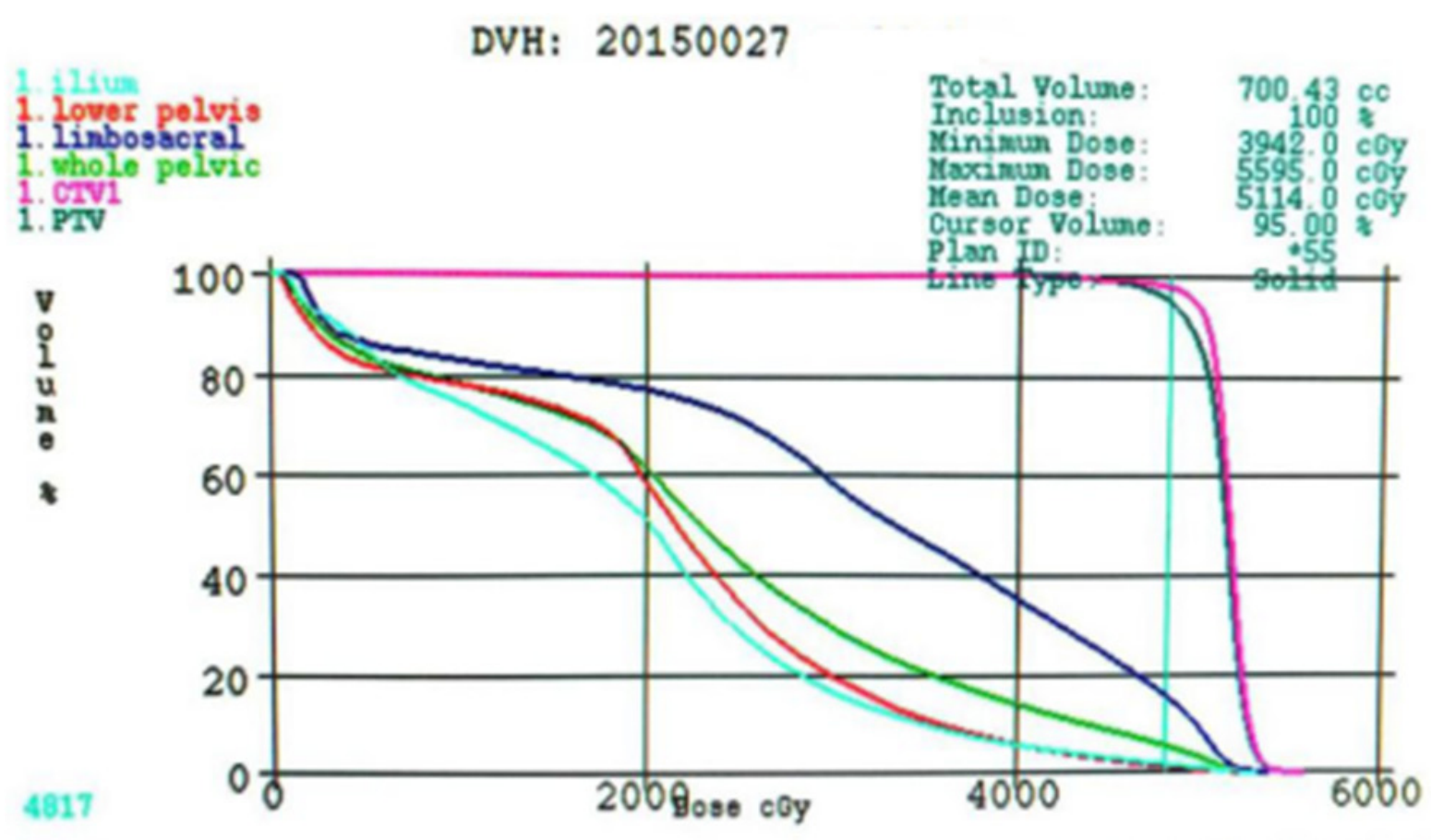

Figure 4: DVH of IMRT plan. The light blue line is ilium, the red line is lower pelvis, the dark blue line is limboscacral, the green line is whole pelvis, the pink line is CTV1 and the dark green line is PTV. Abbreviations: DVH= Dose-volume histogram; IMRT= Intenditymodulated radiotherapy. 
suppression after setting up protective limitations of PBM radiation volume.

\section{MATERIALS AND METHODS}

\section{Patients}

We retrospectively analyzed 50 patients with rectal cancer treated at the Department of Oncology of the Third Hospital of Hebei Medical University from January 2010 to March 2016, and collected clinical data regarding blood cell numbers, diagnosis and treatment. The patients diagnosed with rectal cancer (KPS $\geq 70$ ) and receiving concurrent chemoradiotherapy were included in this study, while patients with discounted radiotherapy, preexisting bone marrow suppression before treatment, or bone metastases were excluded. There were 31 male and 19 female patients with a mean age of 59 (range, 21-78 years). Patients were classified according to the Union for International Cancer Control (UICC) TNM staging system ( $7^{\text {th }}$ edition), and the pathological type of all the tumors was adenocarcinoma.

\section{Radiotherapy}

All patients were in the supine position and immobilized with Med-Tech thermoplastic sheets. Simulation and positioning were performed with Somatomsensation Plus-16 spiral CT scanner (Siemens, Germany) and LAP laser system, and the treatment plans were designed using CMS-Xio4.4 planning system (USA). Fiveor seven-field plan was chosen in the intensity modulated radiation therapy (IMRT). The photon energy of X-ray irradiation was $6 \mathrm{MV}$. Dose to $95 \%$ (D95) of planning target volume (PTV) ranged between 45 to 62 Gy (median dose was $48 \mathrm{~Gy}$ ), and the radiation was performed at 1.8-2.0 Gy daily, 5 times/week, 5-6 weeks. All the patients were treated with clinical linear accelerator (Varian-IX, USA).

\section{Delineation of target volumes}

The gross tumor volume (GTV) included the primary tumor lesions and metastatic lymph nodes. The clinical target volume (CTV) consisted of the GTV and regional draining lymph nodes, including mesentery of rectum, presacral space, iliac blood vessels, and ischiorectal fossa, with the upper bound between L5 and S1 and the lower bound at $2 \mathrm{~cm}$ below the inferior margin of rectal lesion. Ischiorectal fossa was only included when cancer lesion were found in lower rectum. The planning target volume (PTV) was obtained by expanding CTV with a $0.5-1.0 \mathrm{~cm}$ margin to account for set up uncertainty and organ motion.

\section{Delineation of organs at risk (OAR)}

OAR was delineated according to the guidelines for the delineation provided by the Radiation Therapy Oncology
Group (RTOG), including the bladder, the intestine within irradiation range, femoral head, and testicles. We delineated pelvic bone marrow (PBM) to replace hematopoietic bone marrow as first described by Mell et al.[8]. The entire PBM was divided into three subdomains: (1) bilateral ilium bone marrow (IBM) - the iliac crest extending to the upper border of femoral head; (2) lower pelvis bone marrow (LPBM) - the region extending from the superior border of femoral head to the inferior border of ischial tuberosities, including pubes, ischia, acetabula, and proximal femora; (3) lumbosacral spine bone marrow (LSBM) - the region extending from the superior border of L5 to coccyx. (Figure $32 \mathrm{D}$ and 3D pictures of contour of pelvic bone).

\section{Concurrent chemoradiotherapy protocol}

All the patients were given capecitabine orally twice a day $\left(1650 \mathrm{mg} / \mathrm{m}^{2} / \mathrm{d}\right)$ for 5 days every week simultaneously with radiotherapy.

\section{Collection of pelvic dose-volume parameters}

The volumes of IBM, LPBM, LSBM, and PBM receiving $10,15,20,25,30,35$, and $40 \mathrm{~Gy}\left(\mathrm{~V}_{10}, \mathrm{~V}_{15}\right.$, $\mathrm{V}_{20}, \mathrm{~V}_{25}, \mathrm{~V}_{30}, \mathrm{~V}_{35}$, and $\mathrm{V}_{40}$ ) were quantified. The average dose(Dmean) as well as PTV dose and volume were also analyzed. (Figure 4 DVH of IMRT plan).

\section{Grading of acute bone marrow suppression}

We set the initiation and finish of radiotherapy as the starting point and end point of this study. Blood routine examinations were carried out before the initiation of radiotherapy to exclude the patient with pre-existing bone marrow suppression. During the concurrent chemoradiotherapy, we collected complete blood count weekly. Acute bone marrow suppression was graded according to the RTOG acute radiation morbidity scoring criteria [24].

\section{Statistical analyses}

Statistical analyses were performed using SPSS 21.0 software. Quantified data were analyzed by chisquare test or Fisher's exact test. The mean values of two normally distributed samples were compared using $t$ test, and two independent samples without normal distribution were modeled using multivariate logistic regression for screening independent factors. Receiver operating characteristic curve (ROC) analysis was performed to determine the bone marrow dosimetric thresholds of acute bone marrow suppression.

\section{Abbreviations}

UICC: Union for International Cancer Control; IMRT: intensity-modulated radiotherapy; BMS-IMRT: 
bone marrow sparing intensity-modulated radiation therapy; CT: computer tomography; GTV: gross tumor volume; CTV: clinical target volume; PTV: planning target volume; OAR: organ at risk; PBM: pelvic bone marrow; IBM: iliac bone marrow; LPBM: lower pelvis bone marrow; LSBM: lumbosacral spine bone marrow; $\mathrm{V}_{10}$ : the volume of bone marrow receiving $10 \mathrm{~Gy}$ or more; Dmean: the mean dose of bone marrow; DVH: dosevolume histogram; WBC: white blood cell; ANC: absolute neutrophil count; HGB: hemoglobin concentration; PLT: platelet; BMI: body mass index; ROC: receiver operating characteristic curve; AUC: area under curve; TNM: T: tumor, N: lymph node, M: metastasis.

\section{ACKNOWLEDGMENTS}

We would like to thank all the patients involved in the study for their participation.

\section{CONFLICTS OF INTEREST}

None of the authors has any potential conflicts of interest, including financial interests, relationships or affiliations relevant to the subject of this manuscript.

\section{REFERENCES}

1. Chen W, Zheng R, Baade PD, Zhang S, Zeng H, Bray F, Jemal A, Yu XQ, He J. Cancer statistics in China, 2015. CA Cancer J Clin. 2016; 66:115-32. http://doi.org/10.3322/ caac. 21338 .

2. Franco P, Mistrangelo M, Arcadipane F, Munoz F, Sciacero P, Spadi R, Migliaccio F, Angelini V, Bombaci S, Rondi N, Numico G, Ragona R, Cassoni P, et al. Intensity-modulated raduation therapy with simultaneous integrated boost combined with concurrent chemotherapy for the treatment of anal cancer patients:4-year results of a consecutive case series. Cancer Invest. 2015; 33:259-66. http://doi.org/10.31 09/07357907.2015.1028586.

3. Leon O, Guren M, Hagberg O, Glimelius B, Dahl O, Havsteen H, Naucler G, Svensson C, Tveit KM, Jakobsen A, Pfeiffer P, Wanderas E, Ekman T, et al. Anal carcinomaSurvival and recurrence in a large cohort of patients treated according to Nordic guidelines. Radiother Oncol. 2014; 113:352-8. http://doi.org/10.1016/j.radonc.2014.10.002.

4. Melotti A, Aletrio D, Vigna-Taglianti R, Muraglia A, Lastrucci L, Manzo R, Gambaro G, Caspiani O, Micciche F, Deodato F, Pergolizzi S, Franco P, Corvo R, et al. Technical guidelines for head and neck IMRT on behalf of the Italian association of radiation oncology-head and neck working group. Radiat Oncol. 2014; 9:264. http://doi.org/10.1186/ s13014-014-0264-9.

5. Isohashi F, Mabuchi S, Yoshioka Y, Seo Y, Suzuki O, Tamari K, Yamashita M, Unno H, Kinose Y, Kozasa K, Sumida
I, Otani Y, Kimura T, et al. Intensity-modulated radiation therapy versus three-dimensional conformal radiation therapy with concurrent nedaplatin-based chemotherapy after radical hysterectomy for uterine cervical cancer: comparison of outcomes, complications, and dose-volume histogram parameters. Radiation Oncology. 2015; 10: 180. http://doi.org/10.1186/s13014-015-0486-5.

6. Mell LK, Schomas DA, Salama JK, Devisetty K, Aydogan B, Miller RC, Jani AB, Kindler HL, Mundt AJ, Roeske JC, Chmura SJ. Association between bone marrow dosimetric parameters and acute hematologic toxicity in anal cancer patients treated with concurrent chemotherapy and intensity-modulated radiotherapy. Int J Radiat Oncol Biol Phys. 2008; 70:1431-7. http://doi.org/10.1016/j. ijrobp.2007.08.074.

7. Shao L, Luo Y, Zhou D. Hematopoietic stem cell injury induced by ionizing radiation. Antioxid Redox Signal. 2014; 20:1447-62. http://doi.org/10.1089/ars.2013.5635.

8. Mell LK, Kochanski JD, Roeske JC, Haslam JJ, Mehta N, Yamada SD, Hurteau JA, Collins YC, Lengyel E, Mundt AJ. Dosimetric predictors of acute hematologic toxicity in cervical cancer patients treated with concurrent cisplatin and intensity-modulated pelvic radiotherapy. Int J Radiat Oncol Biol Phys. 2006; 66:1356-65. http://doi.org/10.1016/j. ijrobp.2006.03.018.

9. Hayman JA, Callahan JW, Herschtal A, Everitt S, Binns DS, Hicks RJ, Mac Manus M. Distribution of proliferating bone marrow in adult cancer patients determined using FLT-PET imaging. Int J Radiat Oncol Biol Phys. 2011; 79:847-52. http://doi.org/10.1016/j.ijrobp.2009.11.040.

10. Jin J, Meng H, Zhou G, Xu X, Xue Z, Xu X, Wang F, Lu W, Li X, Zhang H, Deng J. Preoperative radiotherapy combined with capecitabine chemotherapy in Chinese patients with locally advanced rectal cancer. J Gastrointest Surg. 2011; 15:1858-65. http://doi.org/10.1007/s11605-011-1637-0.

11. Feng Y, Jin J, Wang X, Xiao Q, Wang W, Wang S, Liu Y, Song Y, Ren H, Fang H, Li N, Li Y, Liu XI, et al. Comparison of concurrent chemoradiotherapy with capecitabine and oxaliplatin versus capecitabine alone in stage II/III rectal cancer patients after radical operation. Chin J Radiat Oncol. 2014; 23:199-204. http://doi. org/10.3760/cma.j.issn.1004-4221.2014.03006.

12. Yamaguchi T, Fukuda M, Yasui H, Okazaki S, Kubo K, Tanaka M, Une Y, Setoguchi Y, Hanada K, Moriyama S, Tani M, Murakami T, Okuchi Y, et al. Oral capecitabine as postoperative adjuvant chemotherapy in stage III colon cancer patients. Gan To Kagaku Ryoho. 2012; 39:389-93.

13. Han K, Cummings BJ, Lindsay P, Skliarenko J, Craig T, Le LW, Brierley J, Wong R, Dinniwell R, Bayley AJ, Dawson LA, Ringash J, Krzyzanowska MK, et al. Prospective evaluation of acute toxicity and quality of life after IMRT and concurrent chemotherapy for anal canal and perianal cancer. Int J Radiat Oncol Biol Phys. 2014; 90:587-94. http://doi.org/10.1016/j.ijrobp.2014.06.061. 
14. Dueñas-González A, Zarbá JJ, Patel F, Alcedo JC, Beslija S, Casanova L, Pattaranutaporn P, Hameed S, Blair JM, Barraclough H, Orlando M. Phase III, open-label, randomized study comparing concurrent gemcitabine plus cisplatin and radiation followed by adjuvant gemcitabine and cisplatin versus concurrent cisplatin and radiation in patients with stage IIB to IVA carcinoma of the cervix. J Clin Oncol. 2011; 29:1678-85. http://doi.org/10.1200/ JCO.2009.25.9663.

15. Klopp AH, Moughan J, Portelance L, Miller BE, Salehpour MR, Hildebrandt E, Nuanjing J, D'Souza D, Souhami L, Small W Jr, Gaur R, Jhingran A. Hematologic toxicity in RTOG 0418: a phase 2 study of postoperative IMRT for gynecologic cancer. Int J Radiat Oncol Biol Phys. 2013; 86:83-90. http://doi.org/10.1016/j.ijrobp.2013.01.017.

16. Huang W, Li Y, Lu W, Tan B. Identification of pelvic dosevolumetric parameters that predict acute bone marrow suppression in concurrent chemoradiotherapy for cervical cancer. Chin J Radiol Med Prot. 2016; 36: 207-10. http:// doi.org/10.3760/cma.j.issn.0254-5098.2016.03.009.

17. Niu L, Wang D. Correlation factors of bone marrow suppression in concurrent chemoradiotherapy for cevical cancer. J Tianjin Med Univ. 2013; 19:48-51. http://doi. org/1006-8147(2013)01-0048-04.

18. Julie DA, Oh JH, Apte AP, Deasy JO, Tom A, Wu AJ, Goodman KA. Predictors of acute toxicities during definitive chemoradiation using intensity-modulated radiotherapy for anal squamous cell carcinoma. Acta Oncol. 2016; 55:208-16. http://doi.org/10.3109/02841 86X.2015.1043396.

19. Bazan JG, Luxton G, Mok EC, Koong AC, Chang DT. Normal tissue complication probability modeling of acute hematologic toxicity in patients treated with intensity-modulated radiation therapy for squamous cell carcinoma of the anal canal. Int $\mathrm{J}$ Radiat Oncol Biol Phys. 2012; 84:700-6. http://doi.org/10.1016/j. ijrobp.2011.12.072.

20. Rose BS, Liang Y, Lau SK, Jensen LG, Yashar CM, Hoh CK, Mell LK. Correlation between radiation dose to 18F-FDG-PET defined active bone marrow subregions and acute hematologic toxicity in cervical cancer patients treated with chemoradiotherapy. Int $\mathrm{J}$ Radiat Oncol Biol Phys. 2012; 83:1185-91. http://doi.org/10.1016/j. ijrobp.2011.09.048.

21. Roeske JC, Lujan A, Reba RC, Penney BC, Yamada DS, Mundt AJ. Incorporation of SPETCT bone marrow imaging into intesity madulated whole-pelvic radiation therapy treatment planning for gynecologic malignancies. Radiother Oncol. 2005; 77:11-7.

22. Wang J, Tian Y, Tang Y, Wang X, Li N, Ren H, Fang H, Feng Y, Wang S, Song Y, Liu Y, Wang W, Li Y, et al. Effect of MRI-guided intensity-modulated radiotherapy with bone marrow protection on hematologic toxicity in patients with rectal cancer undergoing concurrent chemoradiotherapy. Chin J Radiat Oncol. 2016; 25: 244-8. http://doi. org/10.3760/cma.j.issn.1004-4221.2016.03.011.

23. Liang Y, Bydder M, Yashar CM, Rose BS, Cornell M, Hoh CK, Lawson JD, Einck J, Saenz C, Fanta P, Mundt AJ, Bydder GM, Mell LK. Prospective study of functional bone marrow-sparing intensity modulated radiation therapy with concurrent chemotherapy for pelvic malignancies. Int J Radiation Oncol Phys. 2013; 85:406-414. http://doi. org/10.1016/j.ijrobp.2012.04.044.

24. Radiation Therapy Oncology Group. Acute radiation morbidity scoring criteria. http://www.rtog.org. Accessed 15 Dec 2015. 